[Agr. Biol. Chem., Vol. 34, No. 3, p. 432 436, 1970]

\title{
2-Keto-L-gulonic Acid Fermentation
}

\section{Part IV. L-Sorbose Metabolism in Pseudomonas aeruginosa}

\author{
By Toshihiko KanzaKI and Hisayoshi OKazAKI
}

\author{
Microbiological Research Laboratories, Research and Development Division, \\ Takeda Chemical Industries, Litd., \\ Osaka, Japan \\ Received August 9, 1969
}

\begin{abstract}
L-Sorbose metabolism in Pseudomonas aeruginosa IFO 3898 was studied. When the strain was cultivated in L-sorbose medium, L-idonic and 2-keto-L-gulonic acids were detected in the culture broth.

From the results on the metabolism of various sugars and sugar acids with the cell suspension and the metabolites accumulated, the following pathway was proposed for the L-sorbose metabolism in Ps. aeruginosa IFO 3898.

L-Sorbose $\longrightarrow$ L-idose $\longrightarrow$ L-idonic acid $\longrightarrow 2$-keto-L-gulonic acid.
\end{abstract}

It has been reported by Tengerdy" and Huang $^{2}$ that L-sorbose is metabolized by many pseudomonads to 2-keto-L-gulonic acid.

Huang ${ }^{21}$ described that Pseudomonas aeruginosa was not able to produce the acid from L-sorbose. No detailed study on the mechanism of 2-keto-L-gulonic acid formation from L-sorbose has been carried out except our previous studies $^{3,4)}$ in which the metabolic sequence of sorbitol and $L$-sorbose in acetic acid bacteria was presented.

Subsequent studies in this series ${ }^{3 \sim 51}$ demonstrated that organisms belonging to $P_{s}$. aeruginosa which had been described by Huang as a non-producer of 2-keto-L-gulonic acid from $\mathrm{L}$-sorbose were the most prominent bacteria among pseudomonads for the production of

1) R. P. Tengerdy, J. Biochem. Microbiol. Technol. Eng., 3, 241 (1961).

2) H. T. Huang, U. S. Patent, 3043749 (1962).

3) H. Okazaki, T. Kanzaki, M. Doi, K. Nara and K. Motizuki, Agr. Biol. Chem., 32, 1250 (1968).

4) H. Okazaki, T. Kanzaki, K. Sasajima and Y. Terada, ibid., 33, 207 (1969).

5) M. Isono, I. Nakanishi, K. Sasajima, K. Motizuki, T. Kanzaki, H. Okazaki and H. Yoshino, Agr. Biol. Chem., 32, 424 (1968).
2-keto-L-gulonic acid. The present paper deals with the identification of L-sorbose metabolites and the possible metabolic pathway of L-sorbose in Ps. aeruginosa IFO 3898 which was the most active strain in the L-sorbose metabolism.

\section{MATERIALS AND METHODS}

Organism and cultivation. Ps. aeruginosa IFO 3898 was used throughout this study. The seed medium consisted of $1.0 \%$ of L-sorbose and $2.5 \%$ of corn steep liquor, and the main medium was composed of $5.0 \%$ of L-sorbose, $2.5 \%$ of corn steep liquor, $0.01 \%$ of FeSO ${ }_{4} \cdot 7 \mathrm{H}_{2} \mathrm{O}, \quad 0.01 \%$ of $\mathrm{MgSO}_{4} \cdot 7 \mathrm{H}_{2} \mathrm{O}, 0.03 \%$ of $\mathrm{KH}_{2} \mathrm{PO}_{4}, 0.07 \%$ of $\mathrm{K}_{2} \mathrm{HPO}_{4}, 0.05 \%$ of $\mathrm{NaCl}$ and $0.05 \%$ of glycerol.

The seed culture was grown in a $200 \mathrm{ml}$ conical flask containing $20 \mathrm{ml}$ of the seed medium at $30^{\circ} \mathrm{C}$ for $24 \mathrm{hr}$ on a rotary shaker.

One $\mathrm{ml}$ of the seed was transplanted into a $200 \mathrm{ml}$ conical flask containing $20 \mathrm{ml}$ of the main medium and the flask was incubated at $30^{\circ} \mathrm{C}$ for an appropriate period on the rotary shaker.

The $120 \mathrm{hr}$ culture was used for the isolation and identification of the metabolites and the $40 \mathrm{hr}$ culture was employed for the preparation of cell suspensions, respectively. 
Preparation of cell suspensions. After a mild centrifugation $(10 \mathrm{~min}, 1000 \times g)$ to separate large solid materials, the $40 \mathrm{hr}$ culture was recentrifuged for 10 $\min$ at $15,000 \times g$.

The sedimented cells were washed three times with $0.9 \%$ saline solution and suspended in $0.2 \mathrm{M}$ phosphate buffer ( $\mathrm{pH}$ 6.5) amounting to one tenth in volume to the initial culture broth.

Incubation with intact cells. A test tube containing $1 \mathrm{ml}$ of $3 \%$ substrate solution, $1 \mathrm{ml}$ of $0.2 \mathrm{M}$ phosphate buffer ( $\mathrm{pH} 6.5$ ) and $1 \mathrm{ml}$ of the cell suspension was incubated at $30^{\circ} \mathrm{C}$ for 12 or $24 \mathrm{hr}$ with shaking under aerobic conditions.

Cells were removed from the mixture by centrifugation after the reaction had terminated. The resulted clear supernatant was treated with Amberlite IR-120, $\mathrm{H}^{+}$-form to eliminate cations and submitted to paper chromatography or paper electrophoresis.

For the detection of metabolites, silver nitrate reagent ${ }^{6)}$ was employed.

Separation of metabolites. Separation of metabolites was performed by ion-exchange column chromatography with a linear gradient elution of formic acid as described in the previous paper. ${ }^{31}$

Paper chromatography and paper electrophoresis. Toyo Roshi No. 51A was used for both paper chromatography and paper electrophoresis.

Paper chromatography was carried out using the following solvent systems by ascending method: water saturated phenol; pyridine-ethylacetate-acetic acidwater $(5: 5: 1: 3)$ and $n$-butanolacetic acid-water (4:1:1).

Paper electrophoresis was conducted in $0.1 \mathrm{M}$ formate buffer ( $\mathrm{pH} 3.0$ ) for $45 \mathrm{~min}$ at $50 \mathrm{v} / \mathrm{cm}$ and $1 \mathrm{~mA} / \mathrm{cm}$.

\section{RESULTS}

\section{Fractionation of metabolites}

After one liter of the culture broth was centrifuged, the supernatant was passed through a column of Amberlite IR-120 $\mathrm{H}^{+}$-form to eliminate cations and treated with small amounts of activated carbon to remove colored materials.

To separate neutral and acidic components

6) W. W. Trevelyan, D. P. Procter and J. S. Harrison, Nature, 166, 444 (1950). each other, the solution was added to a column of Amberlite IR-45 $\mathrm{OH}^{-}$-form $(4 \times 40 \mathrm{~cm})$.

The acidic components were adsorbed on the column while neutral components passed through the column (Fraction I).

The acidic components were eluted from the column with $0.5 \%$ ammonium hydroxide and the eluate was concentrated in vacuo to a syrup. The syrup was chromatographed on Amberlite CG-400, formate-form $(3 \times 40 \mathrm{~cm})$ with a linear gradient elution of formic acid up to $1.0 \mathrm{~N}$, and the eluate was fractionated into every $20 \mathrm{ml}$ portions. Fractions II and III were tube numbers 30 to 35 and 50 to 61 , respectively.

The paper chromatogram and the paper electrophoregram of the culture filtrate, Fractions II and III are presented in Fig. 1.

\section{Isolation and identification of neutral sugar}

Fraction I was concentrated to a syrup in vacuo, and chilled in a refrigerator to give crystals. Recrystallization from water; $\mathrm{mp}$ $156^{\circ} \mathrm{C},[\alpha]_{\mathrm{D}}^{22}-42^{\circ} \quad(c=1.0$ in water $)$ Anal. Found: $\mathrm{C}, 40.02 ; \mathrm{H}, 6.70$. Calcd. for $\mathrm{C}_{6} \mathrm{H}_{12} \mathrm{O}_{6}$ : $\mathrm{C}, 40.00 ; \mathrm{H}, 6.71 \%$.

These characteristics were the same as those of authentic L-sorbose. The infrared spectrum of the crystals in $\mathrm{KBr}$ disc was also identical with that of L-sorbose.

\section{Isolation and identification of hexonic acid}

As shown in Fig. 2, Fraction II contained only one component behaving as L-idonic acid in paper chromatography using the solvent systems of pyridine-ethylacetate-acetic acidwater $(5: 5: 1: 3)$ and $n$-butanol-acetic acid-water $(4: 1: 1)$.

To isolate the component, Fraction II was concentrated in vacuo to a syrup, neutralized with sodium hydroxide and supplemented with ethanol until the solution became faintly cloudy.

Crystals were obtained by standing the solution in a refrigerator. Recrystallization was performed in the ethanol solution in the same 

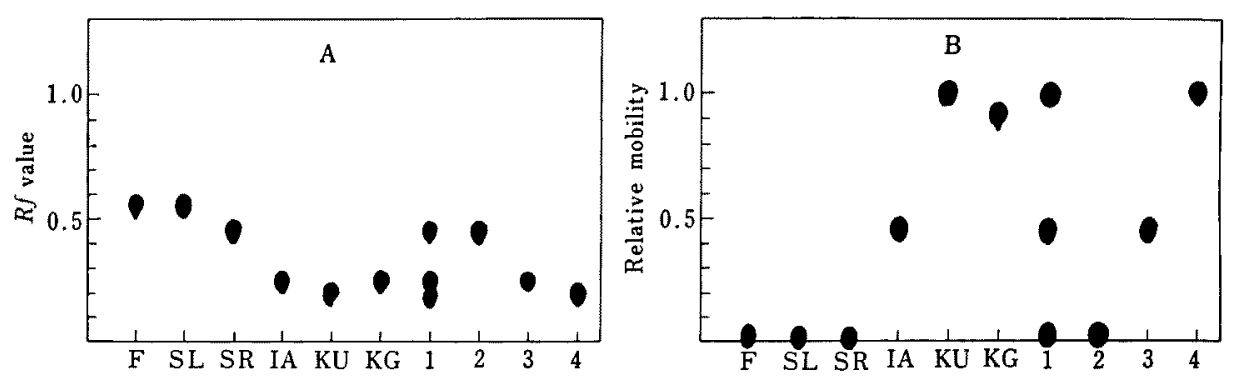

FIG. 1. Paper Chromatogram and Paper Electrophoregram of Culture Filtrate, Fractions I, II and III.

A: Paper chromatogram. Solvent: water-saturated phenol

B : Paper electrophoregram. Solvent: $0.1 \mathrm{M}$ formate buffer $(\mathrm{pH} \mathrm{3.0)}$

1: culture filtrate, 2: Fraction I, 3: Fraction II, 4: Fraction III.

Other abbreviations are the same as those in Fig. 4.
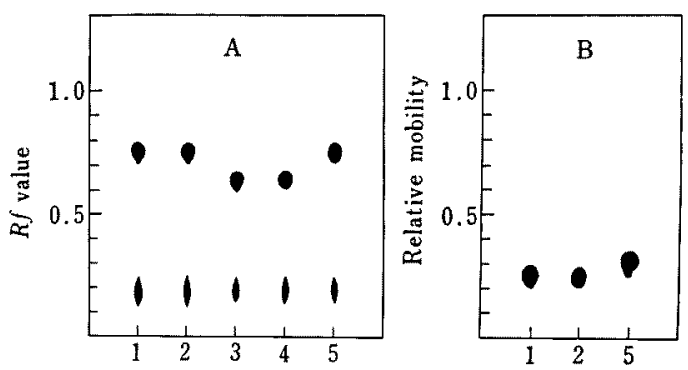

FIG. 2. Paper Chromatograms of Fraction II.

A: Pyridine, ethylacetate, acetic acid, water $(5: 5: 1: 3)$

B : n-Butanol, acetic acid, water (4:1:1)

I : Fraction II, 2: L-idonolactone, 3: D-mannonolactone

4: L-gulonolactone, 5: D-gluconolactone.

Fraction II was treated with acid to give the lactone of the component.

method mentioned above; $\operatorname{mp} 179^{\circ} \mathrm{C},[\alpha]_{\mathrm{D}}^{24}+$ 8.0 $0^{\circ}\left(c=1.0\right.$ in $\left.\mathrm{H}_{2} \mathrm{O}\right)$. Anal. Found: $\mathrm{C}, 30.58$; $\mathrm{H}, 5.49$. Calcd. for $\mathrm{C}_{6} \mathrm{H}_{11} \mathrm{O}_{7} \cdot \mathrm{Na} \cdot \mathrm{H}_{2} \mathrm{O}: \mathrm{C}, 30.52$; $\mathrm{H}, 5.55 \%$. These characteristics indicate that the crystals are sodium L-idonate.

The infrared spectrum of the crystals (Fig. 3) also shows that they are identical with the authenic sodium L-idonate.

Isolation and identification of ketohexonic acid The component of Fraction III behaved as
2-keto-L-gulonic acid by paper electrophoresis as shown in Fig. 1 and 2-keto-D-gluconic acid which was detected in case of acetic acid bacteria $^{3 \prime}$ was not demonstrated.

Fraction III was concentrated in vacuo to give a syrup followed by neutralization with sodium hydroxide. After the solution was supplemented with ethanol until $70 \%(\mathrm{v} / \mathrm{v})$ concentration, the crystals were obtained by standing the ethanol solution in a refrigerator. These were recrystallized by the same method mentioned above and submitted to physical analyses; $\mathrm{mp} 145^{\circ} \mathrm{C},[\alpha]_{\mathrm{D}}^{22}-25.5^{\circ} \quad(c=2.0$ in water). Anal. Found: C, 30.95; H, 4.73. Calcd. for $\mathrm{C}_{6} \mathrm{H}_{9} \mathrm{O}_{7} \cdot \mathrm{Na} \cdot \mathrm{H}_{2} \mathrm{O}: \mathrm{C}, 30.78 ; \mathrm{H}, 4.77 \%$.

The infrared spectrum of the crystals in $\mathrm{KBr}$ disc shows that they are identical with that of authentic sodium 2-keto-L-gulonate.

Oxidation of various substrates by intact cells

To examine the metabolic pattern of sugars and sugar acids by $P$ s. aeruginosa IFO 3898, various substrates were incubated with the intact cells under aerobic conditions.

The data in Figs. 4 and 5 lead us to conclude that L-sorbose was metabolized to 2keto-L-gulonic acid, but $\mathrm{D}$-fructose was probably degradated completely during 12 or 24 $\mathrm{hr}$ incubation since any metabolite was not detected in the reaction mixture. D-Mannose 


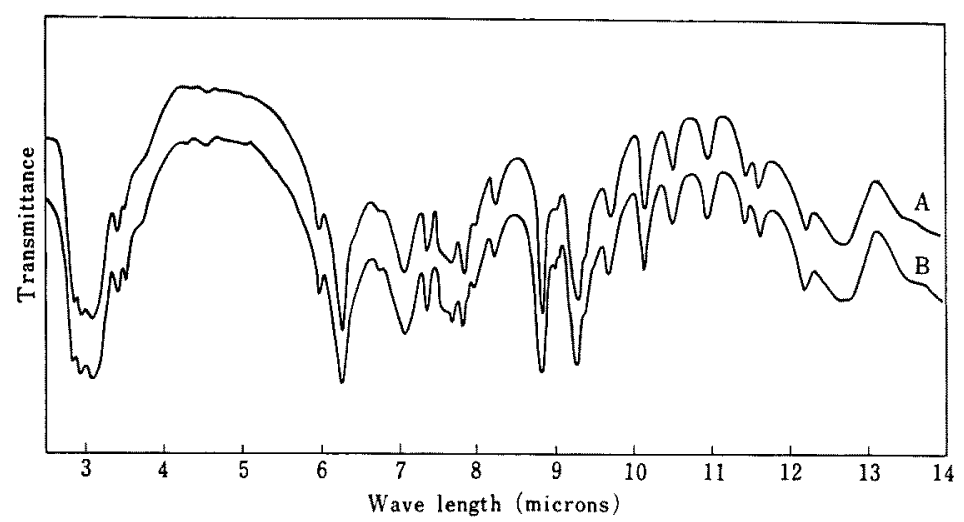

FIG. 3. Infrared Spectra of Crystals from Fraction II and Crystalline Sodium L-Idonate. (KBr disk)

A: Crystals from Fraction II, B: Crystalline sodium L-idonate.

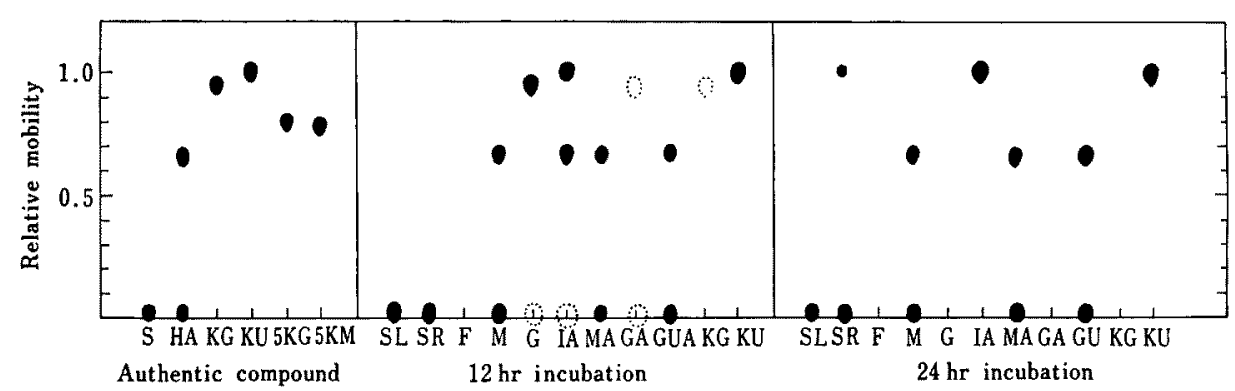

FIG. 4. Paper Electrophoregrams of Incubation Products.

$\mathrm{S}$ : neutral sugar, SL: sorbitol, SR: L-sorbose, F: D-fructose, M: D-mannose,

$G$ : D-glucose, HA: hexonic acid, IA: L-idonic acid, MA: D-mannonic acid,

GA: D-gluconic acid, GUA: L-gulonic acid, KG: 2-keto-D-gluconic acid,

KU: 2-keto-L-gulonic acid, 5KG: 5-keto-D-gluconic acid, 5KM: 5-keto-Dmannonic acid.

gave a substance corresponding to D-mannonic acid. In case of D-glucose, a substance behaving as 2-keto-D-gluconic acid was formed after $12 \mathrm{hr}$ incubation but the greater part of it disappeared after $24 \mathrm{hr}$ incubation. This might be due to a further degradation of the acid to substances other than sugars and sugar acids. Sorbitol was not metabolized.

In sugar acids, substances corresponding to 2-keto-L-gulonic acid and 2-keto-D-gluconic acid were produced from L-idonic acid and D-gluconic acid, respectively.
In case of D-mannonic, L-gulonic and 2-ketoL-gulonic acids, no changes occurred. 2-KetoD-gluconic acid disappeared rapidly from the reaction mixture.

\section{DISGUSSION}

The results presented in this paper show that $P$ s. aeruginosa IFO 3898 accumulates Lidonic and 2-keto-L-gulonic acids in the culture broth when grown on L-sorbose.

On the other hand, as described in the pre- 


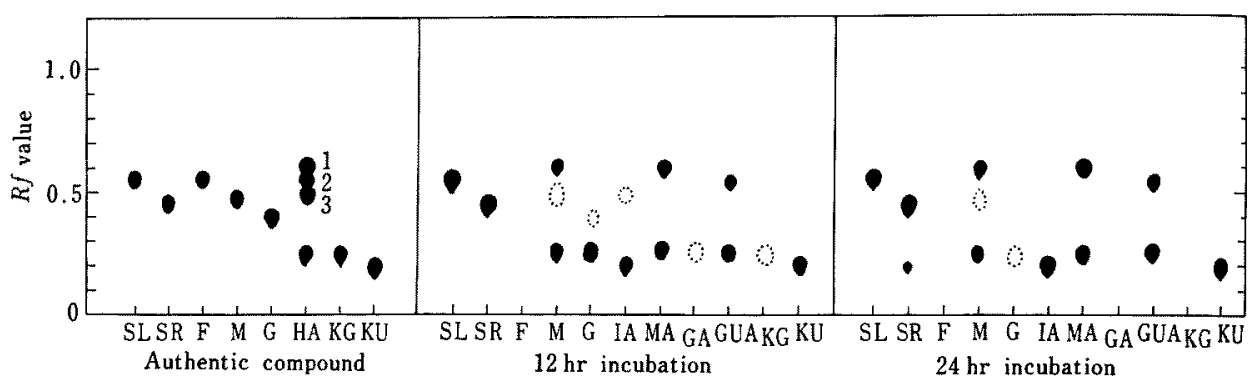

FIG. 5. Paper Chromatograms of Incubation Products.

Abbreviations are the same as those in Fig. 4.

Solvent: water-saturated phenol.

1: D-mannonolactone, 2: L-gulonolactone,

3: L-idonolactone and D-gluconolactone.

vious papers, acetic acid bacteria belonging to Pseudomonadales produced L-sorbose, D-fructose, D-mannonic, L-idonic, 2-keto-D-gluconic, 2-keto-L-gulonic and 5-keto-D-mannonic acids from sorbitol, ${ }^{3 \prime}$ and $\mathrm{D}$-fructose and all of the sugar acids described above were produced from L-sorbose, ${ }^{41}$ respectively. The metabolic activity of the present strain was different from that of Gluconobacter melanogenus in respect that the former could not metabolize sorbitol and did not accumulate $D$-fructose, D-mannonic, 2-keto-D-gluconic, and 5-keto-Dmannonic acids from L-sorbose in the culture broth.

Both organisms however accumulate L-idonic and 2-keto-L-gulonic acids from $\mathrm{L}$-sorbose.

Although D-fructose formation from L-sorbose was not clear in the present paper, the facts that $P$ s. aeruginosa IFO 3898 could grow on L-sorbose and D-fructose disappeared rapidly from the reaction mixture and that L-sorbose was metabolized via $\mathrm{D}$-fructose in acetic acid bacteria" might suggest the possibility of $\mathrm{D}$-fructose formation from $\mathrm{L}$-sorbose by $P_{S}$. aeruginosa IFO 3898.

Under the experimental conditions, D-mannose- or D-mannonic acid-forming system was presumed to be absent in the present strain since D-mannose, D-mannonic and 2-keto-Dgluconic acids were not detected in the broth and also D-mannonic acid was formed and accumulated from D-mannose with intact cells.

As for the 2-keto-L-gulonic acid formation, it seems reasonable to assume that it is formed via L-idonic acid because it is formed from L-idonic acid but not from L-gulonic acid.

The results and possibilities described above suggest that the L-sorbose metabolism in Ps. aeruginosa IFO 3898 involves the following sequence; L-sorbose $\longrightarrow$ L-idose $\longrightarrow$ L-idonic acid $\longrightarrow$ 2-keto-L-gulonic acid.

L-Idose is a possible intermediate and exists between L-sorbose and L-idonic acid based on the studies ${ }^{3,4}$ about the metabolic sequence of sorbitol and L-sorbose in acetic acid bacteria.

Acknowledgements. The authors wish to thank Drs. S. Tatsuoka, R. Takeda and Y. Ishida for their continued interest and encouragement throughout the course of this study. Sincere thanks are also due to Dr. M. Isono and Mr. K. Motizuki for their valuable advices and discussions.

The authentic sodium L-idonate was kindly supplied by Dr. I. Nakanishi and the authors are also indebted to him for the helpful advices about the preparation of crystalline sodium L-idonate. 